\title{
End-tidal carbon dioxide variation after a 100 - and a 500-ml fluid challenge to assess fluid responsiveness
}

\author{
Matthias Jacquet-Lagrèze ${ }^{1 *}$, Florent Baudin ${ }^{1}$, Jean Stéphane David ${ }^{1,2}$, Jean-Luc Fellahi ${ }^{2,3}$, Patrick B. Hu ${ }^{4}$, \\ Marc Lilot ${ }^{2,3}$ and Vincent Piriou ${ }^{1,2}$
}

\begin{abstract}
Background: $\mathrm{EtCO}_{2}$ variation has been advocated replacing cardiac output measurements to evaluate fluid responsiveness (FR) during sepsis. The ability of $\mathrm{EtCO}_{2}$ variation after a fluid challenge to detect $\mathrm{FR}$ in the context of general anaesthesia has not been investigated. Forty patients were prospectively studied. They underwent general anaesthesia for major surgeries. CO was measured by transoesophageal Doppler, and $\mathrm{EtCO}_{2}$ was recorded as well as other haemodynamic parameters [heart rate (HR), mean arterial pressure (MAP), pulse pressure (PP)] at baseline, after 100-ml fluid load over $1 \mathrm{~min}$, and at the end of the $500-\mathrm{ml}$ fluid load. We measured the variation of $\mathrm{EtCO}_{2}$ at $100\left(\Delta \mathrm{EtCO}_{2} 100\right)$ and $500 \mathrm{ml}\left(\triangle \mathrm{EtCO}_{2} 500\right)$, and $\mathrm{ROC}$ curves were generated. $A$ threshold for $\triangle \mathrm{EtCO}_{2}$ to predict $F R$ was determined with receiver operating curves (ROC) analysis. The primary end point was the ability of $\mathrm{EtCO}_{2}$ variation after a 500 -ml fluid load to diagnose FR.
\end{abstract}

Results: Fifteen patients (38\%) were fluid responders. ROC analysis showed that for a threshold of $5.8 \%\left(\triangle \mathrm{EtCO}{ }_{2} 500\right)$, sensitivity was $0.6 \mathrm{IC} 95 \%$ [0.33; 0.86] and specificity was $1.0 \mathrm{IC} 95 \%$ [1.0; 1.0]. An absolute increase of more than $2 \mathrm{mmHg}$ of $\mathrm{EtCO}_{2}$ is specific to diagnose fluid responsiveness (spe $=96[88-100] \%$, sens $=60$ [33-88] \%, AUC $=0.80$ [0.96-0.65]). HR, MAP, and PP variations and $\triangle \mathrm{EtCO}_{2} 100$ did not bring information to predict or diagnose FR. During fluid challenge, the correlation between $\mathrm{Cl}$ variation and $\mathrm{EtCO}_{2}$ variation was $r=0.566, p<0.001$.

Conclusions: During surgery, when alveolar ventilation and $\mathrm{CO}_{2}$ production are constant, $\triangle \mathrm{EtCO}_{2} 500$ is fairly reliable to assess FR. When the variation of $\mathrm{EtCO}_{2}$ is $>5.8 \%$, all patients were responders, but no conclusion could be done when this variation was $<5.8 \% . \triangle \mathrm{EtCO}_{2} 100$ failed to predict $F R$.

Trial registration CPP Lyon Sud Est III ref: 2013-027 B, Number ID RCB: 2013-A00729-36 delivered by the ANSM).

Keywords: Fluid responsiveness, End-tidal carbon dioxide, Diagnosis accuracy

\section{Background}

Excess or lack of fluid can be harmful in the perioperative context. Strategies based on cardiac output optimisation have shown to improve outcome in different kinds of surgeries [1]. The Frank-Starling law implies that the heart of a patient working during the ascending part of the curve will improve cardiac output with an increase

\footnotetext{
*Correspondence: matthias.jl@gmail.com

1 Service d'Anesthésie Réanimation, Centre Hospitalier Lyon Sud, Hospices Civils de Lyon, 165 Chemin du Grand Revoyet, 69495 Pierre-Bénite, France Full list of author information is available at the end of the article
}

in preload: volume responsiveness (VR). Conversely, the heart of a patient working in the range of the plateau of the curve will not improve CO: volume non-responsiveness [2]. Fluid loading is the way to increase preload [3]. Volume responsiveness markers, such as direct cardiac output monitoring or surrogate markers, have been implemented to adjust the amount of fluid to a patient's needs. Static measures such as mean arterial pressure (MAP), pulse pressure (PP), heart rate (HR), and central venous pressure (CVP) cannot predict fluid responsiveness accurately. Dynamic parameters have been developed and have shown to be accurate [4-6]. Parameters 
based on heart and lung interactions are limited by their dependence on relatively large tidal volumes, arrhythmias, or the need for an arterial line [7]. Passive leg raising (PLR) is not convenient during surgery. Mini-fluid challenges have been described as a reliable method to predict VR if cardiac output is monitored [8]. Another approach is to perform a fluid challenge and assess a posteriori its effectiveness. Even though some of published studies show that PP, HR, or MAP variations do not give valuable information about VR after volume expansion; a majority of anaesthesiologists still use these parameters to assess VR. This can be explained by the fact that cardiac output monitoring is thought to be too invasive [9]. The end-tidal carbon dioxide $\left(\mathrm{EtCO}_{2}\right)$ correlates with cardiac output in experimental settings [10]. $\mathrm{EtCO}_{2}$ variation has been recently used to assess cardiac output variation during PLR and allows one to predict fluid responsiveness of septic patients in intensive care units $[11,12]$.

Measuring $\mathrm{EtCO}_{2}$ might be a reliable method to assess the effect of a fluid challenge in the operating room when cardiac output monitoring is not available. But this strategy has not been prospectively evaluated during general anaesthesia with a population including non-septic patients. The correlation between $\mathrm{EtCO}_{2}$ and $\mathrm{CI}$ has been shown to be stronger in a context of circulatory insufficiency than in a normal haemodynamic state [10]. The primary end point was the ability of $\mathrm{EtCO}_{2}$ variation after a 500-ml fluid load to diagnose fluid responsiveness. Secondary end points were to test whether changes in $\mathrm{EtCO}_{2}$ during volume expansion correlate with changes in cardiac output and the ability of the mini-fluid challenge $(100 \mathrm{ml})$ to predict fluid responsiveness.

\section{Methods}

Our institution review board (Comité de Protection des Personnes Lyon Est III ref: 2013-027 B, ANSM Number ID RCB : 2013-A00729-36) approved the study protocol and waived signed informed consent. Inform consent was obtained and notified in the medical record.

\section{Participants}

The study was conducted over a 2.5 -month period in 2013 in a secondary care university hospital in Lyon. Participants were those admitted for emergency surgery with a high risk of haemodynamic disorders.

The decision to administer a fluid bolus for volume expansion was left to the discretion of the attending anaesthesiologist.

Inclusion criteria were patient undergoing general anaesthesia with mechanical ventilation and monitored with an oesophageal Doppler. The attending anaesthesiologist decision to administer a fluid bolus for volume expansion was a prerequisite for the inclusion of the patient. The need of oesophageal Doppler monitoring was defined in our setting as patients undergoing highrisk surgeries or high-risk patients. High-risk surgeries were hip fractures, peritonitis, and abdominal haemostatic surgery. High-risk patients were patients with heart failure or significant arteriopathy. Exclusion criteria were patient refusal age $<18$ years, pregnancy, fluid overload before anaesthesia, patients undergoing laparoscopic surgery, and patients with no available Doppler signals or contraindications to this monitoring technique. All patients meeting the inclusion criteria were included in the study except if they refused to participate if Doppler signal was lacking, or if principal investigators were not available.

\section{Experimental design}

Fluid volume expansion was performed, during the surgery (after the induction of anaesthesia and placement of different monitoring devices). All the data were prospectively recorded, and fluid responsiveness was determined after the fluid bolus and calculated afterthought. The experimental design is detailed in Fig. 1. The manuscript is written to fit with the STARD statement, to allow readers to assess internal and external validity [13].

\section{Fluid used and administration}

Hydroxyethyl starch (Fresenius Kabi, Germany) was used. A total of $500 \mathrm{ml}$ divided into one bolus of $100 \mathrm{ml}$ and remaining $400 \mathrm{ml}$ were administered. The first fluid bolus of $100 \mathrm{ml}$ was administered at a rate of $100 \mathrm{ml}$ in $1 \mathrm{~min}$ (verified using a stopwatch) using a $50-\mathrm{ml}$ syringe. After $1 \mathrm{~min}$, the remaining $400 \mathrm{ml}$ was administered over $11 \mathrm{~min}$. During the $13 \mathrm{~min}$ of fluid administration, there was no modification of the ventilatory settings. Also, no bolus or change in the rate of administration of vasoconstrictor and anaesthetic agents was performed during this period.

\section{Cardiac output monitoring}

Patients were routinely monitored with a transoesophageal Doppler probe (HemoSonic ${ }^{\mathrm{TM}}$ 100, ARROW International ${ }^{\circledR}, 61 \mathrm{~mm}$ length, $<7-\mathrm{mm}$ section. $5 \mathrm{MHz}$ transducer) which enables recording of continuous descending aortic blood velocity, aortic diameter, aortic ejection volume, aortic blood flow, and other valuable parameters such as acceleration of the flow (Acc) and systolic flow time corrected by heart rate (Ftc). Acc has been described to reflect inotropic change [14], and Ftc has been incorrectly described as a measure of left ventricular preload [15]. An algorithm enables cardiac output computation. The same observer (MJL) performed placement of the probes for all patients. 


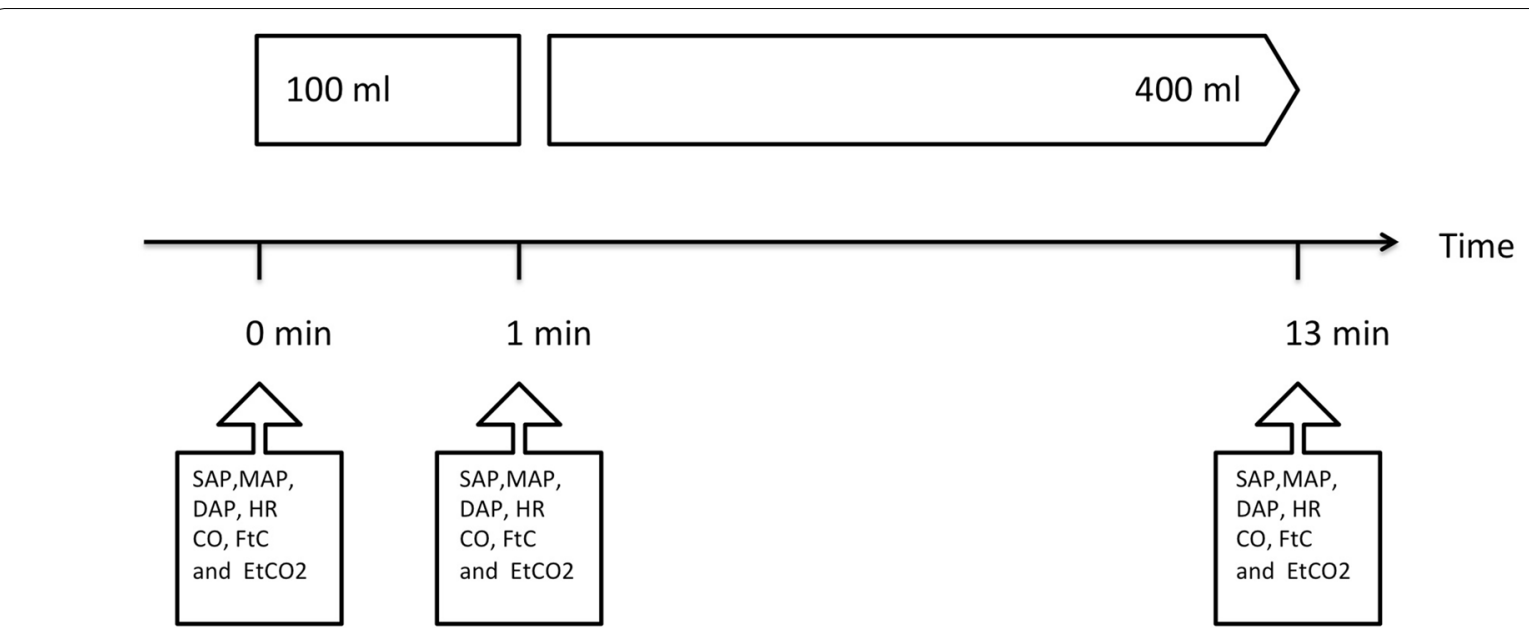

Fig. 1 Experimental design. Data were collected at 0, 1, and 13 min. Mean arterial pressure (MAP), systolic arterial pressure (SAP), diastolic arterial pressure (DAP), corrected systolic flow time (Ftc), and end-tidal carbon dioxide $\left(\mathrm{EtCO}_{2}\right)$

MJL had a good experience with oesophageal monitoring with more than 2-year practice and more than 200 examinations performed. Aortic diameter was visualised and sampled by the transoesophageal probe. The Doppler probe was inserted through the mouth to the place where the maximal aortic blood flow velocity signal could be captured. The quality of the signal was assessed by the visualisation of the two walls of the aorta, and a consistent aortic diameter [16]. Dopplerderived indices were averaged on ten systolic ejections. Cardiac index was calculated as $\mathrm{CO}$ divided by body surface. Measurements were recorded before fluid challenges to assessing variability and the least significant change (LSC).

\section{$\mathrm{EtCO}_{2}$ monitoring}

The Infinity ${ }^{\circledR} \mathrm{EtCO}_{2}$ Microstream SmartPod device was used to monitor $\mathrm{EtCO}_{2}$, a side stream device based on infrared absorption of a specific wavelength. This technology provides measures of $\mathrm{EtCO}_{2}$. The instantaneous values were recorded at 0,1 , and $13 \mathrm{~min}$.

\section{Other data and monitoring}

Perioperative monitoring included continuous electrocardiogram, pulse oximetry, and non-invasive blood pressure every $5 \mathrm{~min}$. Systolic, diastolic, and mean arterial pressures were recorded. Pulse pressure (PP), defined by systolic minus diastolic pressures, was calculated. Airway pressure, peak pressure, plateau pressure, respiratory rate, and tidal volume were monitored as well as partial inspiratory pressures of $\mathrm{O}_{2}$ and $\mathrm{CO}_{2}$. The end-tidal anaesthetic agent concentration of desflurane or sevoflurane was monitored to assess deepness of anaesthesia.

\section{Reference standard}

Patients with more than a $15 \%$ increase in cardiac index with a 500-ml fluid load were defined as fluid responders (R), the others being non-responders (NR) This definition is consistent with many diagnosis accuracy studies of fluid responsiveness. The observer was blind from the reference standard as fluid responsiveness was determined after the end of the fluid challenge and was calculated a posteriori.

\section{Statistical analysis}

We calculated with the method of Obuchowsky et al. [17] that 39 patients were needed in order to detect an area under the ROC curve of 0.75 with a power of 0.9 and an alpha risk of 0.05 . The ratio between responder and non-responder in the studied population was 0.77 . Normal distribution was tested by the d'Agostino-Pearson test. Pairwise comparisons of values were made with the paired Student's $t$ test or Wilcoxon test. The two-tailed Student $t$ test or Mann-Whitney $U$ test was performed for comparisons between responders and non-responders. In cases of relevancy, data were expressed as variations from baseline computed as the difference between final and baseline value divided by the baseline value and expressed as $\Delta \mathrm{CI}$ and $\Delta \mathrm{EtCO}_{2}$ for $\mathrm{CI}$ and $\mathrm{EtCO}_{2}$ variation. Correlations were tested by the Spearman method. The relationships between variables underwent linear regression analysis method. Before volume expansion, multiple measurements were recorded during steady haemodynamic and respiratory conditions defined as no need of vasoconstrictor, fluid challenge, and also no respiratory setting modification and no spontaneous breathing detected on the respirator. To assess the reproducibility of the reference standard and the evaluated test, we performed ten successive measures during a 
stable haemodynamic period. The coefficient of variation was calculated as the standard deviation divided by the mean. The precision was twice the coefficient of variation, and the LSC was computed as 1.96 times the square root time the coefficient of error [18]. The LSC was the minimum change that can be considered as a real change. Data were expressed as mean \pm standard deviation (SD) or as median [interquartile range: IQR] when appropriate. ROC curves were built, and AUC was expressed as $95 \%$ confidence interval. Confidence interval was built with the "bootstraps" technique with 2000 repetitions and the same ratio between case and control.

ROC curves were then compared by the Delong test to a 0.5 built ROC curve [19]. Then, ROC curves were used to define three classes of response: negative, inconclusive, and positive. These classes were defined by the author to implement a $10 \%$ diagnosis tolerance in the analysis as it is proposed in a grey zone approach. An $\mathrm{EtCO}_{2}$ variation with a value lower than the $90 \%$ sensitivity threshold was defined as negative. $\mathrm{An} \mathrm{EtCO}_{2}$ variation greater than the $90 \%$ specificity threshold was defined as positive. Remaining $\mathrm{EtCO}_{2}$ variations were defined as inconclusive. The proportion of the study population within these limits was calculated. Statistical analysis was performed with R Packages, referenced below [20]. Significant results were defined by a $p$ value $<0.05$.

\section{Results}

All patients who met inclusion criteria were screened (Fig. 2). Patient characteristics are given in Table 1. The patients were scheduled for orthopaedic $(65 \%)$ and abdominal surgery ( $35 \%)$. All patients underwent general anaesthesia with mechanical ventilation without spontaneous breathing at the time of the study. Twelve patients had surgery in a context of sepsis and nine had a previous history of cardiac failure (Table 1 ). The precision of $\mathrm{EtCO}_{2}$ was $2.2 \pm 1.3 \%$, and the LSC was $3.2 \pm 0.2 \%$. We did not deplore any adverse events as a consequence of the Doppler monitoring or $\mathrm{EtCO}_{2}$ measurements. We did not have any missing values of $\mathrm{EtCO}_{2}$ or $\mathrm{CO}$ at the three different times of the study.

\section{Responders and non-responders}

Fifteen patients ( $38 \%$ ) were considered to be fluid responders after a $500-\mathrm{ml}$ bolus. CI increased in all patients by 7.8 [3.1; 20.0] \%, in R group by 32 [20; 42] \%, and in NR groups, by 3.7 [0; 7.2] \%. Distribution of $\mathrm{EtCO}_{2}$ variations in responders and non-responders is described in Fig. 3.

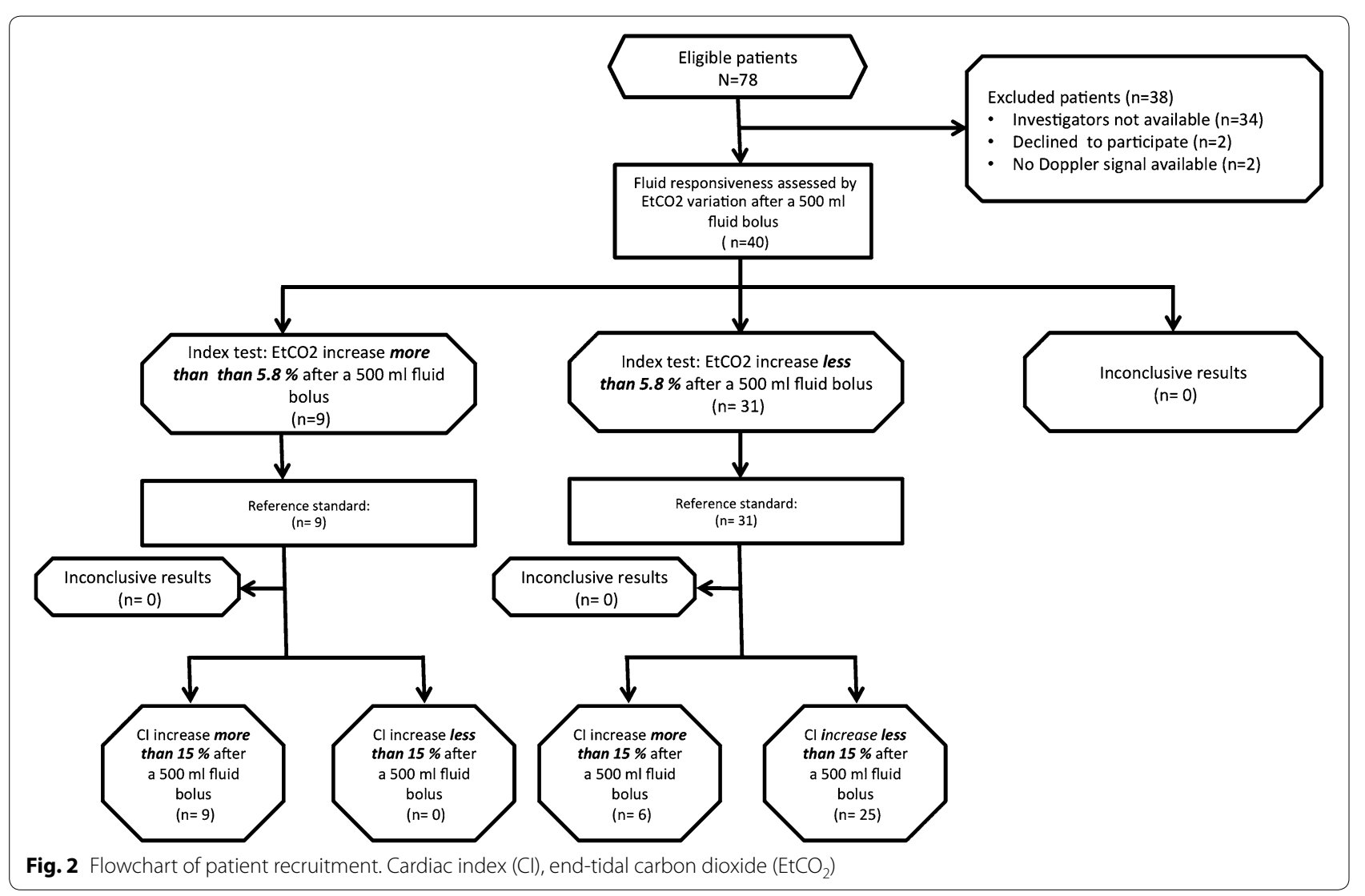


Table 1 Characteristics of the population studied

\begin{tabular}{|c|c|}
\hline Characteristics & $N=40$ \\
\hline Age (years) & 75 [57-92] \\
\hline Male sex & $17(43)$ \\
\hline Weight (kg) & $69[51-86]$ \\
\hline Height (cm) & $166[156-177]$ \\
\hline BMI $\left(\mathrm{kg} \mathrm{m}^{-2}\right)$ & $25[20-30]$ \\
\hline \multicolumn{2}{|l|}{ Surgery } \\
\hline Orthopaedic surgery & $26(65)$ \\
\hline General surgery & $14(35)$ \\
\hline Sepsis & $12(30)$ \\
\hline \multicolumn{2}{|l|}{ Antecedent } \\
\hline ASA score & $2.0[1.6-2.8]$ \\
\hline Atrial fibrillation & $5(13)$ \\
\hline Cardiac failure & $9(23)$ \\
\hline COPD & $4(10)$ \\
\hline \multicolumn{2}{|l|}{ Treatment prior surgery } \\
\hline Beta blockers & $12(30)$ \\
\hline Other antiarrhythmic agents & $5(13)$ \\
\hline \multicolumn{2}{|l|}{ Ventilation } \\
\hline Tidal volume $\left(\mathrm{ml} \mathrm{kg}^{-1}\right)$ & $6.6[4.9-8.4]$ \\
\hline PEEP $\left(\mathrm{cmH}_{2} \mathrm{O}\right)$ & $5[4-7]$ \\
\hline $\mathrm{FiO}_{2}(\%)$ & $58[50-70]$ \\
\hline $\mathrm{EtCO}_{2}(\mathrm{mmHg})$ & 31 [28-34] \\
\hline $\mathrm{SpO}_{2}(\%)$ & 99 [97-100] \\
\hline \multicolumn{2}{|l|}{ Anaesthesia protocol } \\
\hline Sufentanil & $39(98)$ \\
\hline Propofol TIVA & $5(13)$ \\
\hline Halogenated & $35(88)$ \\
\hline Curare & $16(40)$ \\
\hline Regional anaesthesia & $14(35)$ \\
\hline \multicolumn{2}{|l|}{ Vasoconstrictors } \\
\hline Vasoconstritor use & $11(28)$ \\
\hline Phenylephrine $\left(\mu \mathrm{g} \mathrm{kg}^{-1} \mathrm{~min}^{-1}\right)$ & $0.2[0.0-0.3]$ \\
\hline
\end{tabular}

Data are expressed as median and [25th-75th] or as number and proportion of patients $(n=40)$. Body mass index (BMI), chronic obstructive pulmonary disease (COPD), positive end-expiratory pressure (PEEP), fraction of inspired oxygen $\left(\mathrm{FiO}_{2}\right)$, end-tidal carbon dioxide $\left(\mathrm{EtCO}_{2}\right)$, arterial oxygen partial pressure $\left(\mathrm{PaO}_{2}\right)$, arterial carbon dioxide partial pressure $\left(\mathrm{PaCO}_{2}\right)$, pulse oxygen saturation $\left(\mathrm{SpO}_{2}\right)$, total intravenous anaesthesia (TIVA), vasoconstrictor (VC)

\section{Description of the Variation of $\mathrm{Cl}$ and $\mathrm{EtCO}_{2}$, pulse} pressure, heart rate, Ftc, ventilatory change and end-tidal anaesthetic agent concentration during volume expansion Baseline haemodynamic and respiratory parameters were not significantly different between fluids responders and non-responders (Table 2). No significant differences were found for $\mathrm{Vt}$ and minute ventilation between before and after fluid expansion and between both groups at each moment (Table 2). The end of the trial, after the 500-ml volume expansion, showed a significant increase in $\mathrm{CI}$ and $\mathrm{EtCO}_{2}$ in the responders group and the Ftc increased in both groups (Table 2). The end-tidal anaesthetic

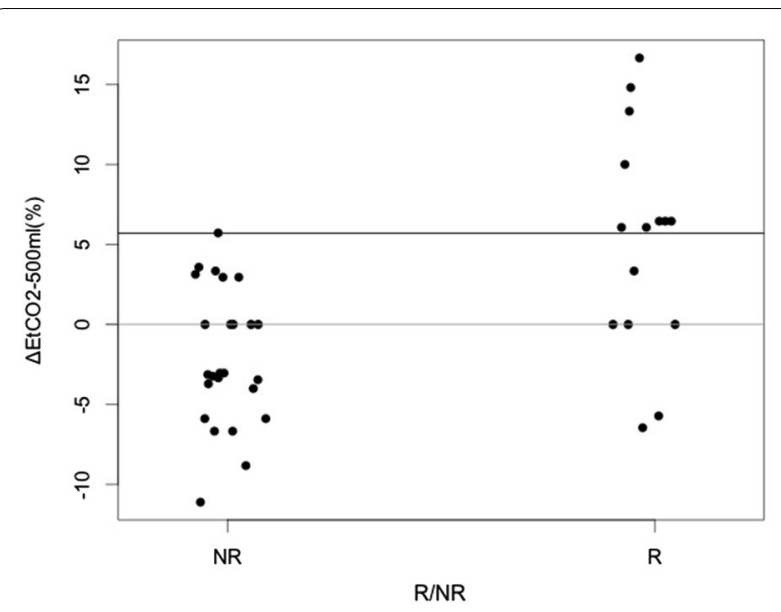

Fig. $3 \mathrm{EtCO}_{2}$ variation in responder and non-responder. Variation of end-tidal carbon dioxide after $500 \mathrm{ml}\left(\triangle \mathrm{EtCO}_{2}-500 \mathrm{ml}\right)$, responders (R) defined as patients who increased cardiac index more than $15 \%$ after fluid expansion and non-responders (NR) defined as patients who increased cardiac index $<15 \%$ after fluid expansion

agent concentration of desflurane or sevoflurane variation between before and after the fluid challenge was 2.6 $[-1.8 ; 11.4] \%$ in the $\mathrm{R}$ group and $0[0 ; 11.1] \%$ in the NR group with no significant difference $(p=0.9)$.

\section{Correlation between $\mathrm{EtCO}_{2}$ and $\mathrm{Cl}$}

The Spearman correlation test between $\mathrm{CI}$ and $\mathrm{EtCO}_{2}$ was not significant $(r=0.178, p=0.272)$. However, there was a significant correlation $(r=0.566, p<0.001)$ between $\mathrm{CI}$ variation $(\Delta \mathrm{CI})$ and $\mathrm{EtCO}_{2}$ variation $\left(\Delta \mathrm{EtCO}_{2}\right)$. The slope of the linear regression was 0.172 .

\section{Ability of $\Delta \mathrm{EtCO}_{2}$ to predict fluid responsiveness after a mini-fluid challenge $(100 \mathrm{ml})$}

The correlation between $\mathrm{EtCO}_{2}$ variation and $\mathrm{CI}$ variation after a 100-ml fluid challenge was significant: $r=0.39$, $p=0.013$. The change in $\mathrm{EtCO}_{2}$ after a $100-\mathrm{ml}$ infusion provided an AUC-ROC $=0.74$ [0.60; 0.89]; threshold $=3.0 \%$; sens $=33[13-60] \%$, spe $=100[100-100] \%$.

\section{Ability of $\Delta \mathrm{EtCO}_{2}$ to diagnose fluid responsiveness after a 500-ml volume expansion}

The area under the receiver operating characteristic curve (ROC-AUC), sensitivity, specificity, positive predictive value, and negative predictive value likelihood ratios are given in Table $3 . \Delta \mathrm{EtCO}_{2}$ after a $500-\mathrm{ml}$ expansion $\left(\Delta \mathrm{EtCO}_{2} 500\right)$ was able to diagnose fluid responsiveness with a threshold of $5.8 \%$. In a pragmatic approach, an absolute increase of more than $2 \mathrm{mmHg}$ of $\mathrm{EtCO}_{2}$ can diagnose fluid responsiveness (spe $=96$ [88-100] \%, sens $=60[33-88] \%$, AUC $=0.80[0.96-0.65])$. The AUC-ROC for heart rate variation $\left(\Delta \mathrm{HR}_{500}\right)$, MAP 
Table 2 Haemodynamic data before and after a 500-ml fluid load in responders and non-responders

\begin{tabular}{|c|c|c|c|}
\hline & TO & $\mathrm{T} 500 \mathrm{ml}$ & $p$ value \\
\hline \multicolumn{4}{|c|}{$\mathrm{HR}\left(\mathrm{min}^{-1}\right)$} \\
\hline $\mathrm{R}$ & $69[65 ; 75]$ & $73[66 ; 76]$ & 0.27 \\
\hline$N R$ & $69[61 ; 77]$ & $70[63 ; 74]$ & 0.33 \\
\hline \multicolumn{4}{|c|}{ MAP (mmHg) } \\
\hline R & $59[51 ; 66]$ & $67[55 ; 83]$ & 0.12 \\
\hline$N R$ & $63[58 ; 67]$ & $64[56 ; 72]$ & 0.47 \\
\hline \multicolumn{4}{|c|}{ SAP $(\mathrm{mmHg})$} \\
\hline R & $91[84 ; 99]$ & $111[92 ; 115]$ & 0.08 \\
\hline$N R$ & $95[88 ; 107]$ & $95[90 ; 112]$ & 0.40 \\
\hline \multicolumn{4}{|c|}{ DAP $(\mathrm{mmHg})$} \\
\hline R & $50[41 ; 54]$ & $55[44 ; 66]$ & 0.07 \\
\hline$N R$ & $50[47 ; 56]$ & $53[45 ; 60]$ & 0.60 \\
\hline \multicolumn{4}{|c|}{ PP (mmHg) } \\
\hline $\mathrm{R}$ & $44[39 ; 51]$ & $49[41 ; 61]$ & 0.16 \\
\hline$N R$ & $46[37 ; 51]$ & $44[40 ; 60]$ & 0.42 \\
\hline \multicolumn{4}{|c|}{$\mathrm{Ftc}(\mathrm{s} / \sqrt{ } \mathrm{s})$} \\
\hline$R$ & 312 [296; 329] & $331[325 ; 371]$ & $<0.01$ \\
\hline$N R$ & $305[289 ; 322]$ & 334 [303; 369] & $<0.01$ \\
\hline \multicolumn{4}{|c|}{$\mathrm{EtCO}_{2}(\mathrm{mmHg})$} \\
\hline $\mathrm{R}$ & $31[30,32]$ & $33[31 ; 33]$ & 0.02 \\
\hline NR & $32[29 ; 34]$ & $31[28,32]^{\#}$ & 0.04 \\
\hline \multicolumn{4}{|c|}{ MV (L/min) } \\
\hline R & $5.1[4.4 ; 6.9]$ & $5.2[4.4 ; 6.9]$ & 0.52 \\
\hline$N R$ & $6.4[5.8 ; 7.2]$ & $6.4[5.7 ; 7.3]$ & 0.81 \\
\hline
\end{tabular}

Comparison of responders (R) and non-responders (NR): two-tailed Wilcoxon's rank test was performed between variables to compare before and after fluid expansion. Mann-Whitney $U$ test was performed to compare responders to nonresponders. Signs ${ }^{\#}$ for significant results comparing R and NR. Significant results comparing before and after fluid expansion are given by $p$ value. Heart rate (HR), mean arterial pressure (MAP), diastolic arterial pressure (DAP), systolic arterial pressure (SAP), pulse pressure (PP), corrected systolic flow time (Ftc), cardiac index $(\mathrm{Cl})$, end-tidal carbon dioxide $\left(\mathrm{EtCO}_{2}\right)$, and minute ventilation (MV). Data are expressed as median and [25th-75th]

variation $\left(\Delta \mathrm{MAP}_{500}\right)$, and $\mathrm{PP}$ variation $\left(\Delta \mathrm{PP}_{500}\right)$ was not significantly different from 0.5 . ROC curve of $\Delta H R_{500}$, $\Delta \mathrm{MAP}_{500}$ and $\Delta \mathrm{EtCO}_{2} 500$ is shown in Fig. 4.

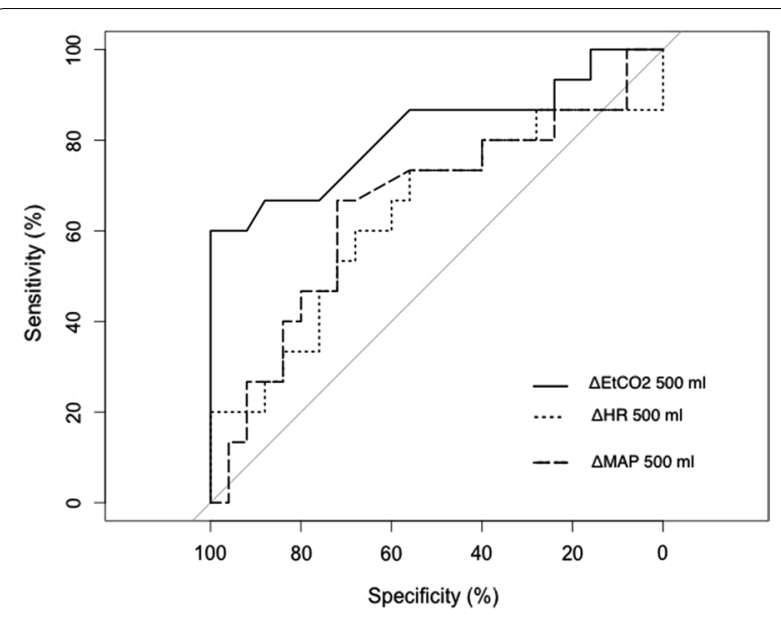

Fig. 4 ROC curves of $\mathrm{EtCO}_{2}, \mathrm{MAP}$, and $\mathrm{HR}$ variation to assess fluid responsiveness after a 500-ml fluid load. Mean arterial pressure (MAP), end-tidal carbon dioxide $\left(\mathrm{EtCO}_{2}\right)$, and heart rate $(\mathrm{HR})$ variation after 500-ml fluid load to diagnose responders (R). $\triangle \mathrm{EtCO}, \triangle \mathrm{MAP}$, and $\triangle \mathrm{HR}$ are the variation $\%$ of each hemodynamic parameter after a $500-\mathrm{ml}$ fluid load

\section{Clinical ranking of the response with a $10 \%$ diagnosis tolerance}

After a 500-ml fluid load, $\mathrm{EtCO}_{2}$ variation within the population can be classified as follows: 10 patients had a negative test, 10 patients had a positive test, and 20 patients had an inconclusive test.

\section{Discussion}

This study shows that in a context where alveolar ventilation and $\mathrm{CO}_{2}$ production are constant, the change in $\mathrm{EtCO}_{2}$ provides information to assess the $\mathrm{CI}$ changes during a 500-ml volume expansion. $\mathrm{EtCO}_{2}$ variation after a mini-fluid challenge is probably not usable to predict the response to a fluid bolus of $500 \mathrm{ml}$.

Three factors can explain a change in $\mathrm{EtCO}_{2}$ : pulmonary blood flow (usually equal to cardiac output), $\mathrm{CO}_{2}$ metabolic production, and alveolar ventilation [21]. Naturally, if two of these factors are constant, the change in

Table 3 Main characteristics of ROC curves built for hemodynamic variables of interest

\begin{tabular}{|c|c|c|c|c|c|c|c|c|c|c|}
\hline & AUC & $\begin{array}{l}\text { Best } \\
\text { thresholds (\%) }\end{array}$ & $\begin{array}{l}\text { Compared } \\
\text { with } A U C=0.5\end{array}$ & Specificity & Sensitivity & PPV & NPV & LR+ & LR- & $\begin{array}{l}\text { Youden } \\
\text { index }\end{array}$ \\
\hline $\operatorname{varEtCO}{ }_{2} 500$ & $0.82[0.67 ; 0.97]$ & 5.89 & 0.006 & $1[1.0 ; 1.0]$ & $0.6\left[\begin{array}{ll}0.33 & 0.87\end{array}\right]$ & 1.0 & 0.81 & Infinite & 0.4 & 0.6 \\
\hline $\operatorname{varEtCO} 2100$ & $0.74[0.60 ; 0.89]$ & 3.0 & 0.034 & $1[1.0 ; 1.0]$ & $0.33[0.13 ; 0.6]$ & 1.0 & 0.68 & Infinite & 0.67 & 0.33 \\
\hline $\operatorname{varMAP} 500$ & $0.62[0.44 ; 0.83]$ & & 0.31 & & & & & & & \\
\hline $\operatorname{varPP}_{500}$ & $0.62[0.43 ; 0.82]$ & & 0.31 & & & & & & & \\
\hline $\operatorname{varHR}_{500}$ & $0.65[0.44 ; 0.82]$ & & 0.29 & & & & & & & \\
\hline $\mathrm{FtC}$ & $0.49[0.37 ; 0.67]$ & & 0.09 & & & & & & & \\
\hline
\end{tabular}

Mean arterial pressure (MAP), pulse pressure (PP), heart rate (HR), corrected systolic flow time (Ftc), and end-tidal carbon dioxide (EtCO $)$. Data are expressed as variation from baseline (i.e., $\triangle \mathrm{EtCO}_{2}$ for $\mathrm{EtCO}_{2}$ variation) after different volumes of infused fluid: 100 and $500 \mathrm{ml}$. Area under the curve (AUC), positive predictive value (PPV), negative predictive value (NPV), positive likelihood ratio ( $\mathrm{LR}+$ ), negative likelihood ratio (LR-) 
the third factor can explain the variation of $\mathrm{EtCO}_{2}$. Two mechanisms can also explain $\mathrm{EtCO}_{2}$ variation. First, a fluid challenge increases venous return and pulmonary blood flow; thus, a greater amount of $\mathrm{CO}_{2}$ delivery to the lungs and removal by alveolar ventilation should be observed. Second, a fluid challenge recruits collapsed pulmonary blood capillaries and, therefore, reduces West zones 1 and 2 and increases zone 3 [22]. Consequently, the ventilation/perfusion ratio decreases and dead space is reduced enabling more $\mathrm{CO}_{2}$ to be extracted by alveolar ventilation.

Our results are consistent with previously published studies. $\mathrm{EtCO}_{2}$ has been described to be able to track CI changes in experimental [10] and clinical settings [23]. Additionally, changes in $\mathrm{EtCO}_{2}$ have been used in many clinical situations as cardiac resuscitation for monitoring blood flow generated by precordial compression [24] or assessing the prognosis of cardiac arrest [25, 26]. Two recent studies focusing on patients with septic shock using PLR and volume expansion have shown a significant correlation between changes in $\mathrm{EtCO}_{2}$ and CI. Some anaesthesiologists already assess fluid responsiveness by measuring $\mathrm{EtCO}_{2}$ variation during a fluid challenge, though this strategy has not been specifically evaluated [27]. As previously described, the correlation between the absolute values of $\mathrm{EtCO}_{2}$ and CI was not significant. This is explained by the fact that except for very low $\mathrm{CI}, \mathrm{EtCO}_{2}$ is mainly influenced by many other factors than CI. Of course, during the short meantime of a volume expansion, these factors can be considered as unchanged.

The threshold value of the $\mathrm{EtCO}_{2}$ variation after 500$\mathrm{ml}$ volume infusion was $5.8 \%$, or an increase of $2 \mathrm{mmHg}$, which is low, but $\mathrm{EtCO}_{2}$ is a very stable variable if no modification of ventilation or cell metabolism occurs, so even a small change can be significant. This idea is reinforced by the fact that the least significant change (LSC) is smaller than the best threshold for a 500-ml load. Moreover, this is about the same threshold as the previously published one $[11,12]$. Again, the threshold is near the LSC, and it seems to us that it would be hard to use in the clinical settings for a 100-ml load.

In previous studies, the correlation between changes in $\mathrm{EtCO}_{2}$ and $\mathrm{CI}$ was stronger during PLR than during volume expansion $[11,12]$. Three main explanations can be given.

First, a passive leg raising is shorter than a fluid challenge. This increases the risk of a confounding factor such as ventilation or metabolism variation to be present.

Second, the study protocol was applied during anaesthesia for a surgery and not in a context of circulatory insufficiency. The link between $\mathrm{EtCO}_{2}$ and $\mathrm{CI}$ is predicted to be weaker when there is no circulatory insufficiency [10].

Third, the preload increase induced by a mini-fluid challenge is inferior compared with a passive leg raising. Our results concerning the mini-fluid challenge are consistent with a study performed recently in a population of septic patients [28]. From our point of view, as long as the fluid challenge is great enough and the infusion time is short, changes in $\mathrm{EtCO}_{2}$ could be used as a surrogate for CO changes.

As expected, HR, PP, and MAP variations were unable to predict fluid responsiveness. In a pragmatic approach, with a clinical $10 \%$ tolerance of sensitivity and specificity, as in the grey zone model, we can only conclude for half of the patients. Of course, these results are poorly discriminant. Nevertheless, the discrimination is higher than with parameters mostly used to assess fluid responsiveness as MAP and HR.

We acknowledge that there are some limitations. The variation of $\mathrm{EtCO}_{2}$ could be explained by variation in $\mathrm{VCO}_{2}$ due to variation in the depth of anaesthesia, but we did not find a significant difference between both groups in the end-tidal anaesthetic agent concentration. We did not use a specific device to monitor the depth of anaesthesia. Nevertheless, end-tidal anaesthetic agent concentration remains the reference to assess depth of anaesthesia [29].

The weak correlation between $\mathrm{EtCO}_{2}$ variation, and CI variation after a mini-fluid challenge was largely explained by the imprecision of both measurements: in fact, at that same time the mean variation of $\mathrm{CI}$ and $\mathrm{EtCO}_{2}$ in the responder group is under the least significant change in the $\mathrm{EtCO}_{2}$ and $\mathrm{CI}$.

Our patients benefited from protective mechanical ventilation with positive end-expiratory pressure and low tidal volumes for its positive effect [30]. Consequently, we did not compare our data to pulse pressure variation (PPV) or stroke volume variation (SVV) because we set the tidal volume under $8 \mathrm{ml} / \mathrm{kg}$. These settings make SVV or PPV unable to predict fluid responsiveness [6,31].

The AUC-ROC after a 500-ml fluid load has a lower confidence interval which is below 0.75 . Accordingly, our study has not sufficient power to exclude the fact that the AUC in the population is below this limit. Therefore, we cannot exclude the fact that $\mathrm{EtCO}_{2}$ variation after a 500$\mathrm{ml}$ fluid load could be of limited clinical interest according to Ray et al. [32].

To conclude in a setting with a constant alveolar ventilation and $\mathrm{CO}_{2}$ production, if no data on cardiac output or pulse pressure variation are available, $\mathrm{EtCO}_{2}$ is the only parameter that was discriminant to assess fluid responsiveness. When the variation of $\mathrm{EtCO}_{2}$ is $>5.8 \%$, 
all patients were responders, but no conclusion could be done when this variation was $<5.8 \%$. A $100-\mathrm{ml}$ minifluid challenge was not discriminant and cannot be used to predict fluid responsiveness regarding the least significant change in the $\mathrm{EtCO}_{2}$. Conversely to widespread belief, MAP, PP, and HR variations were not accurate in predicting fluid responsiveness. The strategy of fluid expansion based on $\mathrm{EtCO}_{2}$ variation could be a part of a haemodynamic optimisation protocol regarding its high specificity and its tremendous advantage upon classical cardiac output monitoring to be non-invasive, at no additional cost, and available in all operating rooms.

\section{Authors' contribution \\ MJL conceived of the study and the design of the study, collected data, per- formed statistical analysis, and wrote the manuscript. VP, FB, JLF, ML and PBH participated in the design of the study and helped with the statistical analysis and helped to draft the manuscript. JSD participated in the study's design and coordination and helped to draft the manuscript. All authors read and approved the final manuscript.}

\section{Author details}

${ }^{1}$ Service d'Anesthésie Réanimation, Centre Hospitalier Lyon Sud, Hospices Civils de Lyon, 165 Chemin du Grand Revoyet, 69495 Pierre-Bénite, France. ${ }^{2}$ Université Claude-Bernard, Lyon 1. Campus Lyon Santé Est, 8 Avenue Rockefeller, 69008 Lyon, France. ${ }^{3}$ Service d'Anesthésie Réanimation, Centre Hospitalier Louis Pradel, Hospices Civils de Lyon, 59 Boulevard Pinel, 69500 Bron, France. ${ }^{4}$ Irvine's Department of Anaesthesiology and Perioperative Care, University of California, 333 City Blvd W \#2150, Orange, CA 92868, USA.

\section{Competing interests}

The authors declare that they have no competing interests.

\section{Funding source}

All authors declare no funding source.

Received: 1 October 2015 Accepted: 6 April 2016

Published online: 22 April 2016

\section{References}

1. Hamilton MA, Cecconi M, Rhodes A. A systematic review and metaanalysis on the use of preemptive hemodynamic intervention to improve postoperative outcomes in moderate and high-risk surgical patients. Anesth Analg. 2011;112:1392-402.

2. Katz AM. Ernest Henry Starling, his predecessors, and the "Law of the Heart". Circulation.2002;106:2986-92.

3. Guyton AC. Determination of cardiac output by equating venous return curves with cardiac response curves. Physiol Rev. 1955;35:123-9.

4. Michard F, Boussat S, Chemla D, Anguel N, Mercat A, Lecarpentier Y, Richard C, Pinsky MR, Teboul JL. Relation between respiratory changes in arterial pulse pressure and fluid responsiveness in septic patients with acute circulatory failure. Am J Respir Crit Care Med. 2000;162:134-8.

5. Cannesson M, Attof Y, Rosamel P, Desebbe O, Joseph P, Metton O, Bastien $\mathrm{O}$, Lehot J-J. Respiratory variations in pulse oximetry plethysmographic waveform amplitude to predict fluid responsiveness in the operating room. Anesthesiology. 2007;106:1105-11.

6. De Backer D, Heenen S, Piagnerelli M, Koch M, Vincent J-L. Pulse pressure variations to predict fluid responsiveness: influence of tidal volume. Intensive Care Med. 2005;31:517-23.

7. Lansdorp B, Lemson J, van Putten MJAM, de Keijzer A, van der Hoeven JG, Pickkers P. Dynamic indices do not predict volume responsiveness in routine clinical practice. Br J Anaesth. 2012;108:395-401.

8. Muller L, Toumi M, Bousquet P-J, Riu-Poulenc B, Louart G, Candela D, Zoric L, Suehs C, de La Coussaye J-E, Molinari N, Lefrant J-Y, AzuRéa Group. An increase in aortic blood flow after an infusion of $100 \mathrm{ml}$ colloid over 1 minute can predict fluid responsiveness: the mini-fluid challenge study. Anesthesiology. 2011;115:541-7.

9. Cannesson M, Pestel G, Ricks C, Hoeft A, Perel A. Hemodynamic monitoring and management in patients undergoing high risk surgery: a survey among North American and European anesthesiologists. Crit Care [Internet] 2011 [cited 2013 Nov 26]; 15: R197. http://www.biomedcentral. com/content/pdf/cc10364.pdf.

10. Ornato JP, Garnett AR, Glauser FL. Relationship between cardiac output and the end-tidal carbon dioxide tension. Ann Emerg Med. 1990;19:1104-6.

11. Monnet X, Bataille A, Magalhaes E, Barrois J, Le Corre M, Gosset C, Guerin L, Richard C, Teboul J-L. End-tidal carbon dioxide is better than arterial pressure for predicting volume responsiveness by the passive leg raising test. Intensive Care Med 2013;39: 93-100. doi:10.1007/ s00134-012-2693-y.

12. Monge García MI, Gil Cano A, Gracia Romero M, Monterroso Pintado R, Pérez Madueño V, Díaz Monrové JC. Non-invasive assessment of fluid responsiveness by changes in partial end-tidal $\mathrm{CO}_{2}$ pressure during a passive leg-raising maneuver. Ann Intensive Care. 2012;2:9.

13. Rennie D. Improving reports of studies of diagnostic tests: the STARD initiative. JAMA. 2003;289:89-90.

14. Monnet X, Robert J-M, Jozwiak M, Richard C, Teboul J-L. Assessment of changes in left ventricular systolic function with oesophageal Doppler. $\mathrm{Br}$ J Anaesth. 2013;111:743-9.

15. Singer M. The FTC is not an accurate marker of left ventricular preload. Intensive Care Med. 2006;32:1089 (author reply 1091).

16. Singer M, Bennett ED. Noninvasive optimization of left ventricular filling using esophageal Doppler. Crit Care Med. 1991;19:1132-7.

17. Obuchowski NA. ROC curves in clinical chemistry: uses, misuses, and possible solutions. Clin Chem. 2004;50:1118-25. doi:10.1373/ clinchem.2004.031823.

18. Cecconi M, Rhodes A, Poloniecki J, Della Rocca G, Grounds RM. Benchto-bedside review: the importance of the precision of the reference technique in method comparison studies-with specific reference to the measurement of cardiac output. Crit Care [Internet] 2009 [cited 2014 Apr 3]; 13: 201. http://www.biomedcentral.com/1364-8535/13/201.

19. Fawcett T. An introduction to ROC analysis. Pattern Recogn Lett. 2006;27:861-74. doi:10.1016/j.patrec.2005.10.010.

20. Robin X, Turck N, Hainard A, Tiberti N, Lisacek F, Sanchez J-C, Müller M. PROC: an open-source package for R and S+ to analyze and compare ROC curves. BMC Bioinform. 2011;12:77.

21. West JB. State of the art: ventilation-perfusion relationships. Am Rev Respir Dis. 1977;116:919-43.

22. Fougères $E$, Teboul J-L, Richard C, Osman D, Chemla D, Monnet X. Hemodynamic impact of a positive end-expiratory pressure setting in acute respiratory distress syndrome: importance of the volume status. Crit Care Med. 2010;38:802-7.

23. Shibutani K, Muraoka M, Shirasaki S, Kubal K, Sanchala VT, Gupte P. Do changes in end-tidal $\mathrm{PCO}_{2}$ quantitatively reflect changes in cardiac output? Anesth Analg. 1994;79:829-33.

24. Gudipati CV, Weil MH, Bisera J, Deshmukh HG, Rackow EC. Expired carbon dioxide: a noninvasive monitor of cardiopulmonary resuscitation. Circulation 1988;77: 234-9. doi:10.1161/01.CIR.77.1.234.

25. Levine RL, Wayne MA, Miller CC. End-tidal carbon dioxide and outcome of out-of-hospital cardiac arrest. N Engl J Med 1997; 337: 301-6. doi:10.1056/ NEJM199707313370503.

26. Grmec $\mathrm{S}$, Klemen P. Does the end-tidal carbon dioxide $\left(\mathrm{EtCO}_{2}\right)$ concentration have prognostic value during out-of-hospital cardiac arrest? Eur J Emerg Med Off J Eur Soc Emerg Med. 2001;8:263-9.

27. Youngblood SC, Markan S, Palvadi R. Cardiac output monitoring is already standard. Anesthesiology. 2013;119:725-6.

28. Xiao-Ting W, Hua Z, Da-Wei L, Hong-Min Z, Huai-Wu H, Yun L, Wen-Zhao C. Changes in end-tidal $\mathrm{CO}_{2}$ could predict fluid responsiveness in the passive leg raising test but not in the mini-fluid challenge test: a prospective and observational study. J Crit Care. 2015;. doi:10.1016/j.jcrc.2015.05.019.

29. Avidan MS, Jacobsohn E, Glick D, Burnside BA, Zhang L, Villafranca A, Karl L, Kamal S, Torres B, O'Connor M, Evers AS, Gradwohl S, Lin N, Palanca BJ, Mashour GA. Prevention of intraoperative awareness in a high-risk surgical population. N Engl J Med. 2011;365:591-600. doi:10.1056/ NEJMoa1 100403. 
30. Amato MBP, Barbas CSV, Medeiros DM, Magaldi RB, Schettino GP, Lorenzi-Filho G, Kairalla RA, Deheinzelin D, Munoz C, Oliveira R, e al. Effect of a protective-ventilation strategy on mortality in the acute respiratory distress syndrome. N Engl J Med 1998; 338: 347-54. doi:10.1056/ NEJM199802053380602.

31. Vallée F, Richard JCM, Mari A, Gallas T, Arsac E, Verlaan PS, Chousterman B, Samii K, Genestal M, Fourcade O. Pulse pressure variations adjusted by alveolar driving pressure to assess fluid responsiveness. Intensive Care Med. 2009:35:1004-10.

32. Ray P, Le Manach Y, Riou B, Houle TT. Statistical evaluation of a biomarker. Anesthesiology [Internet] 2010 [cited 2015 Dec 16]; 112: 1023-40. http://www.researchgate.net/profile/Yannick_Le_Manach/ publication/42109369_Statistical_Evaluation_of_a_Biomarker/ links/546632380cf25b85d17f5bc8.pdf.

\section{Submit your manuscript to a SpringerOpen ${ }^{\circ}$ journal and benefit from:}

- Convenient online submission

\section{- Rigorous peer review}

- Immediate publication on acceptance

- Open access: articles freely available online

- High visibility within the field

- Retaining the copyright to your article 